\title{
Forecasting financial problems in emerging capital markets
}

\begin{abstract}
The advent of the Asian Financial Crisis (AFC) in the Southeast Asia in 1997 is an appealing case for research work in assessing corporate financial distress. From international perspective, AFC is a product of contagion effect that spread from Thailand and consequently to the other Asian countries. Domestically, the AFC has resulted a sudden economic slump and corporate failures in these economies. This paper examines the corporate failure before the 1997 Asian Financial Crisis in three emerging capital markets namely Malaysia, Singapore and Thailand, and develops, tests, and analyses a model for classifying and predicting financial distress. A failure classification model based on multiple discriminant analysis was utilised to classify listed corporations from these countries for the 1980 to 1996 period. The model is tested on a sample of 33 Malaysian, 17 Singaporean and 52 Thailand failed firms and similar number of non-failed firms in the respective countries as a control sample. The failure prediction model developed successfully discriminates between failed and non-failed listed firms at the rate of $86 \%, 82 \%$ and $71 \%$ of Malaysian, Singaporean and Thailand firms respectively. Further validation of findings show that the predictive accuracy was significantly better than chance. (C) EuroJournals Publishing, Inc. 2006.
\end{abstract}

Keyword: Corporate failure, Financial ratios, Prediction model, Discriminant analysis 